\title{
ANALYSIS OF VOICE DISORDERS AT SHREE BIRENDRA HOSPITAL
}

\author{
Reeba Karki ${ }^{1}$, Kiran Rai ${ }^{1}$ \\ ${ }^{1}$ Department of ENT-HNS, Shree Birendra Hospital
}

\begin{abstract}
Introduction: Voice disorder is a common condition encountered in ENT-HNS clinic. This study was conducted to analyze the prevalence, presentation and to assess the management of patients with voice disorders at Shree Birendra Hospital.

Method: A prospective study of all the patients with voice disorders attending in ENT-HNS outpatient department of Shree Birendra Hospital from November 15 2010 to May 15 2011 were evaluated both clinically and with fibro optic laryngoscope. Each patient was assessed by consultant ENT-Head and Neck surgeon and speech therapist. Patient with psychological disorders and those without fibro optic laryngoscope findings were excluded in the study.
\end{abstract}

Results: Total numbers of 120 patients were analyzed. There were 88(73\%) females and 32 (27\%) males. Most common voice disorder was habitual dysphonia among 70 patients (58.3\%) followed by true vocal cord nodule in 20 patients (16.6\%). Majority of the patients (79.16\%) with voice disorders were managed by speech therapy and only 25 (21\%) patients required surgical intervention.

Conclusion:Voice disorders are frequent occurrence and most of these can be treated with voice therapy alone. Only few require surgical intervention.

Key words: dysphonia, fibro-optic laryngoscope, voice therapy.

\section{INTRODUCTION}

Every human voice is unique due to anatomical, physiological, psychological, cultural, sociolinguistic and behavioral factors. Our voices changes throughout our lifetime, but there are also minor and sometimes major fluctuation throughout a day. There have been tremendous advances in the understanding of voice disorders and their management in recent years. Disorders of voice-where the predominant symptom is dysphonia (impaired) and aphonia (absent) must be distinguished from disorders of speech, articulation and language. Voice disorders are largely a manifestation of laryngeal pathology. About 6-23\% of 5-18 years old population have some form of voice problem ${ }^{1,2}$. Voice disorders can be highly subjective: that is, what may be a serious problem for one person may present little difficulty to another. ${ }^{3,4}$ Some of this has to do with a given person's expectations, but a key factor is vocal demand.
Videolaryngostroboscopic examination of vocal folds remains gold standard for clinical assessment of larynx. Treatment can be conservative, including treatment of acid reflux, upper respiratory tract infection and allergies or voice therapy which includes, vocal hygiene program, relaxation and breathing techniques, voice therapy exercise (strengthening the vocal cords, relaxing and breathing exercises and exercises for improve). When all nonsurgical treatment modalities have been exhausted and significant vocal functional limitations exists, then phonomicrosurgery is indicated.

In recent years, we have noticed increased number of patients in out patient department with various voice disorders. This study was conducted to audit the types of voice disorder at our hospital.

\section{Correspondence:}

Maj. Dr. Reeba Karki

Department of ENT-HNS, Shree Birendra Hospital.

E-mail: karkireeba@hotmail.com

Cell No.: 9841403909 


\section{METHOD}

This was a prospective study carried out in 120 patients from November $15^{\text {th }} 2010$ to May 15 2011 in ENT-HNS department of Shree Birendra hospital. All the patients who presented to our department with voice disorder were thoroughly evaluated by consultant ENT surgeon and speech therapist. A diagnosis was made by careful history taking, clinical examination and examination with fibro optic laryngoscope. Patient with psychological disorders and those without fibro optic laryngoscope findings were excluded from the study. All the patients were submitted to voice therapy under direct supervision of speech therapist and those who were not responding to voice therapy were subjected to surgical management. Details of clinical presentation, examination, fibro optic laryngoscopy findings were recorded and data was analyzed using Microsoft Excel 2003.

\section{RESULTS}

Total numbers of 120 patients were enrolled in the session. Minimum age was 15 years and maximum was 71 years with mean age 40 years. There were $88(73 \%)$ females and $32(27 \%)$ males. Most common age group was $36-40$ years (44), followed by $31-35$ years (20), 26-30 years (16). Most common pathology of voice disorder was habitual dysphonia in 70 (58.3\%) patients, followed by true vocal cord nodules in 20 (16.6\%) patients whereas the least common pathology were puberphonia and stuttering occurring in 3 patients each (2.5\%).

Majority of the patients were treated conservatively 95(79\%), where as phonomicrosurgery were carried out on 25 (21\%) patients not responding to non-surgical treatment and with benign and suspicious mass in endolarynx, followed by histopathological examination of the excised tissue. After surgery, a period of one week of total voice rest was advised to almost all patients.

Table 1. demographic data

\begin{tabular}{|c|l|}
\hline $\begin{array}{c}\text { Sex Distribution } \\
\text { Male } \\
\text { Female }\end{array}$ & $32(27 \%)$ \\
$88(73 \%)$ \\
\hline Age distribution & \\
$<20$ years & $3(2.5 \%)$ \\
$21--40$ & $84(70 \%)$ \\
$41-60$ & $24(20 \%)$ \\
$>60$ & $9(7.5 \%)$ \\
\hline
\end{tabular}

Table 2: Pathological distribution

\begin{tabular}{|c|l|}
\hline Causes of voice disorder & \\
Habitual dysphonia & $70(58.33 \%)$ \\
Vocal nodules & $20(16.66 \%)$ \\
Vocal polyp & $8(6.66 \%)$ \\
Carcinoma larynx & $7(5.83 \%)$ \\
Laryngitis & $5(4.16 \%)$ \\
Vocal cord palsy & $4(3.33 \%)$ \\
Puberphonia & $3(2.5 \%)$ \\
Stuttering & $3(2.5 \%)$ \\
\hline
\end{tabular}

Fig 2: Treatment

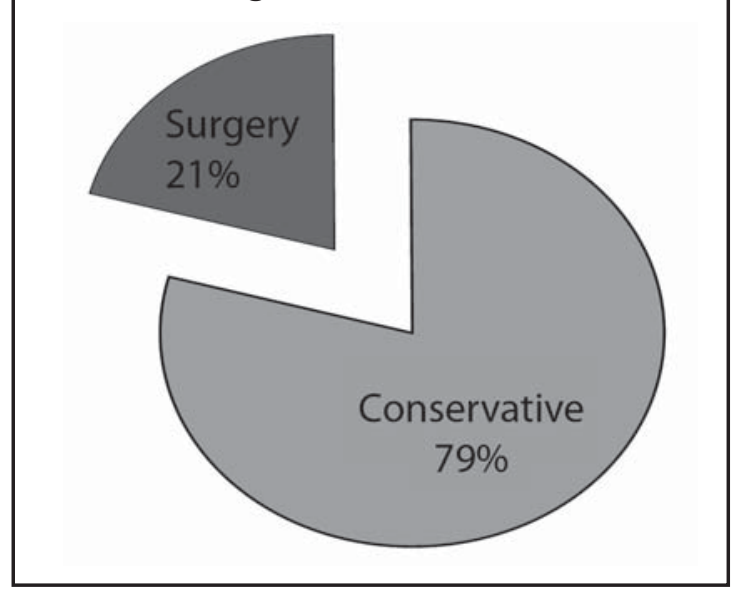

\section{DISCUSSION}

Any condition that affects the performance of the voice producing organ-the larynx can cause a voice disorder. Habitual dysphonia is the most common voice disorder. Data on voice disorder ranged from 0.65 to $15 \%$ in general population. ${ }^{5,6}$ In our study the mean age of patients was around 40 years with female predominance of 1:3, but there has been a shift over time with regard to the prevalence of sex ratios. 7,8

Certain laryngeal diseases (e.g. cancer, leukoplakia) are more prevalent in men than women. ${ }^{9}$ Many infections, chronic illness and trauma contribute to non-organic dysphonias. The most frequently encountered disorders in our study was habitual dysphonia with adduction gap followed by vocal nodules.

Treatment, if required for any form of voice disorders consists of identifying precipitating causes and treating as appropriate, such as: vocal hygiene, dietary and life style advice; ${ }^{10}$ vocal therapy targeted at specific muscles groups; $11,12,13,14$ laryngeal manipulation; ${ }^{15,16}$ behavioral therapy; ${ }^{17}$ medical treatment, for example of extraosophageal reflux; and surgical treatment (phonomicrosurgery, laryngeal framework surgery, injection augmentation). Most of the patients in our study were managed conservatively with speech therapy. Speech therapy is directed not only to the impairment domain (i.e. the larynx), but usually assists the patients to address the participation, activity limitation and distress which arise from the underlying impairment. ${ }^{18}$ Micro laryngeal surgeries and biopsy of excised tissue were indicated in our study to patients with benign and suspicious lesions in endolarynx who fail voice therapy and remain symptomatic as in the other study. ${ }^{19}$ Aim of our surgery was precise excision of the vocal lesion with no exposure or damage to the underlying ligament as similar to other study. ${ }^{20}$

After biopsy report most of the benign lesion needed no any specific treatment whereas malignant lesion were 
presented among 7 (5.83\%) patients and they were treated as per the staging of malignancies. In ours study every carcinoma patients were treated with palliative treatment such as radiotherapy or chemotherapy.

\section{CONCLUSION}

The spectrum of voice disorders seen in OPD is very wide. The commonest being habitual dysphonia with finding

\section{REFERENCES}

1. Aran D, Ekelman B. Preschoolers with language disorders-10 years later. Journal of Speech and Hearing Research. 1984;27:232-44.

2. Silverman EM. Incidence of chronic hoarseness among school age children. Journal of Speech and hearing Disorders. 1975;40:211-5.

3. Fawcus M. The causes and classification of voice disorder In: Freeman M, Fawcus M (eds). Voice disorders and their management, 3rd edn. London: Whurr Publishers, 2000: 47-68.

4. Verdolini K. Voice disorders. In; Tomblin JB, Morris HL, Spriestersbach DC (eds). Diagnosis in speech-language pathology. San Diego, CA: Singular press, 1994: 247-306.

5. Moreley D. A ten-year survey of speech disorders among university students. Journal of Speech and Hearing disorders. 1952;17:25-31.

6. Lauguaite J. Adult voice screening. Journal of Speech and Hearing Disorders. 1972;37:147-51.

7. Russell A, Oates J, Greenwood K. Prevelence of voice problems in teachers. Journal of Voice. 1998;12:467-79.

8. Smith E, Kirchner L, Taylor M, Hoffman H, Lenke T. Voice problems Among teachers, differences by gender and teaching characteristics. Journal of voice. 1998;12:328-34.

9. Herrington $\mathrm{HB}$, Lee $\mathrm{L}$, Stemple J, Niemi $\mathrm{K}$, McHone $\mathrm{M}$. Description Of Laryngeal pathologies by age, sex and occupation in a treatment-Seeking sample. Journal of Speech and Hearing disorders. 1998;53:57-65. of adduction gap among them. With careful assessment, voice therapy and occasionally surgical intervention, most dysphonias can be corrected or improved. More research is still required particularly with regard to laryngopharyngeal reflux which is often cited as an important cause of hoarseness but is still poorly understood.

10. Mathieson L. Hyperfunctionasl voice disorders. The voice and its disorders. London:Whurr Publishers, 2001:145-85.

11. Mathieson L. The voice and its disorders. London: whurr Publishers,2001.

12. Harris S. speech therapy for dysphonia. The Voice Clinic Handbook. London: Whurr Publishers Ltd, 1998:139-206.

13. Ramig LO, Verdolini K. Treatment efficacy: Voice disorders. Journal Of Speech, Language and Hearing Research. 1998;41:101-16.

14. Sellars C, Carding PL, Deary U, Mac Kenzie K, Wilson JA Characteriazation of effective primary voice therapy for dysphonia.Journal of Laryngology and Otology. 2002;116:1014-8.

15. Liberman J. Principles and techniques of manual therapy:Applications in the management of dysphonia. The Voice Clinic Handbook.London: Whurr PublishersLtd, 1998; 91-138.

16. Roy N, Bless DM. Manual circumlaryngeal techniques in the assessment and treatment of voice disorders. Opinion in Otolaryngology and Head and Neck surgery. 1998;6:151-5.

17. Enderby P. Therapy Outcome Measures: Speech-Language Pathology Technical Manual. London: Singular, 1997.

18. Pedersen M, McGlashan J. Surgical versus non-surgical interventions for vocal cord nodules. Cochrane Database Syst Rev. 2001;(2):CD001934.

19. Bouchayer M, Cornut G. Phonosurgery for benign vocal fold lesions. Gilbralter: The 3Ears Company Limited, 1994. 